\title{
Attitudes to Malocclusion in a Nigerian School Population
}

\author{
Emmanuel 0. Ajayi and Yetunde O. Ajayib
}

\begin{abstract}
The aim of this study was to determine attitudes to malocclusion and orthodontic treatment need among school children in Lagos, Nigeria. The sample consisted of 120 randomly selected school children, 66 boys (55\%) and 54 girls (45\%) aged 10-12 years in Lagos State, Southwestern region of Nigeria. The study was conducted with a fixed choice questionnaire and the need for orthodontic treatment was assessed with the WHO-FDI basic method for recording occlusal traits, 1979. The results showed that most children (61.7\%) were satisfied with their dental appearance with no significant sex differences while thel0-year-old children expressed significantly higher level of dissatisfaction with their teeth arrangement $(\mathrm{P}<0.05)$. There was an urgent orthodontic treatment need in $11.7 \%$ of the children who had handicapping malocclusion while treatment was also considered necessary in $19.2 \%$. The need for orthodontic treatment was significantly higher in the girls than boys $(P<0.05)$. The half $(50 \%)$ of the children that needed professionally determined urgent orthodontic treatment expressed satisfaction with the arrangement of their teeth. This study revealed a moderate concern and knowledge of malocclusion among sample of Nigerian children evaluated with a need for orthodontic treatment in less than one third.
\end{abstract}

\section{INTRODUCTION}

Malocclusion describes a spectrum of deviation from the normal or ideal occlusion to very severe anomalies. Malocclusion was classified under the heading of Handicapping Dentofacial anomaly by the World Health Organisation" and was described as "an anomaly

$\begin{aligned} \text { KEY WORDS: } & \text { Malocclusion, Attitudes, Orthodontic } \\ & \text { treatment need, }\end{aligned}$

arthodontic Unit, Department of Preventive Dentistry, College of Medical Sciences, University of Benin, Benin City, Nigeria.

'Department of Restorative Dentistry, college of Medicine, University of Lagas, Nigeria.

Correspondence: Dr. Emmanuel O. Ajayi Orthodontic Unit, Department of Preventive Dentistry, College of Medical Sciences, University of Benin, Benin city, Nigeria. Tel: +234-802-300-3683 Email: buskyet@yahoo.com

( CMS UNIBEN JMBR 2006; 5 (1): 16-23 which causes disfigurement or which treatment if the disfigurement or functional defect is, or is likely to be an obstacle to the patient's physical or emotional well being."

Several orthodontic researches have revealed that an important motivation for orthodontic treatment is usually improvement in dentofacial appearance. ${ }^{2-6}$ The studies on the attitude of children and adolescents to malocclusion conducted in various researches especially among the Caucasians also revealed increased concern for dental appearance and desire for orthodontic treatment. ${ }^{2,4,7,8}$ The importance of the patient's perception of dental appearance and need for orthodontic treatment cannot be over-emphasised as it is the patients who receive treatment and need to gain satisfaction from improved aesthetics and function. ${ }^{9}$ Birkeland et $\mathrm{al}^{10}$ also observed that investigation of the level of self-worth and 
Attitudes to Malocclusion in a Nigerian School Population 17

dental appearance in children could facilitate the determination of subjective need for orthodontic treatment.

The earlier epidemiological studies carried out on malocclusion among Nigerian subjects were focused on prevalence of malocclusion but there is dearth of information on the attitudes of Nigerian children to malocclusion. Therefore, the determination of level of satisfaction with dental aesthetics and perceived need for orthodontic treatment among school population who are of age range that could benefit from orthodontic therapy will aid in the planning and provision of orthodontic care and services in Nigeria. The information obtained will also assist the orthodontists in educating and providing advice to potential orthodontic patients and their parents. ${ }^{4}$

The purpose of the present study therefore was to determine attitude to malocclusion and desire for orthodontic treatment among a sample of Nigerian school children in Lagos and compare the results to findings in other populations.

\section{MATERIALS AND METHODS}

The study population consisted of randomly selected one hundred and twenty children, 66 boys (55\%) and 54 girls (45\%) within the age range of $10-12$ years (mean age of 10.8 years) attending senior class of primary schools in Lagos State of Nigeria. None of the children had any previous history of orthodontic treatment.

The attitudes to malocclusion were determined from the response to fixed choice questionnaire (Table 1) while the need for orthodontic treatment was assessed by clinical examination of each child using the WHO-FDI basic method for recording occlusal traits. ${ }^{11}$ The author (E.O.A) performed all the examinations of the children in their classroom with the illumination provided by natural light. The children examined were classified into four groups according to their need of treatment 0: not necessary; 1 : doubtful; 2: necessary; 3: urgent (Appendix 1)

Approval was obtained from the schools' administrator and the parents who agreed to have their children examined gave informed consent.

The intra-examiner reproducibility was assessed by re-examination of twenty randomly selected school children two weeks after their initial examination and reliability was satisfactory with the kappa value of 0.88 indicating almost perfect agreement. ${ }^{12}$

The EPI-INFO version 6 statistical software ${ }^{13}$ was used for data entry and analysis. Chi-square test was used to determine statistical significance between frequencies and association between variables with $\mathrm{P}<0.05$ regarded as significant.

\section{RESULTS}

Table 1 shows the distribution of the responses obtained to the questionnaire on the attitude of the subjects to malocclusion between the sexes. $61.7 \%$ of the children expressed satisfaction with the arrangement of their teeth and no significant gender difference was observed (Table 1a) . 51.7\% of the subjects desired to have their teeth straightened (Table 1b) while 55.8\% of the children considered well-aligned teeth to be important for overall facial appearance (Table 1c) .

There was a statistical difference in perception of dental aesthetics between the age groups $(P<0.05)$ and the highest distribution of dissatisfaction with teeth arrangement was observed in 10-year-old children as shown in Table 2.

Table 3 shows that $60 \%$ of the children examined were considered not to require any orthodontic treatment while $19.2 \%$ and $11.7 \%$ of the subjects would require necessary and urgent orthodontic treatment respectively. The need for orthodontic treatment was also significantly different between the boys and girls with the $31.5 \%$ of the girls required necessary orthodontic treatment $(P<0.05)$. 
No significant association was found between concern for dental aesthetics and desire for orthodontic treatment among the sexes (Table 4).

Half of the subjects (50\%) that needed professionally determined urgent orthodontic treatment expressed satisfaction with their teeth arrangement (Table 5) .

\section{DISCUSSION}

There was no gender difference in the subjective assessment of dental appearance in this sample of Nigerian children with $61.7 \%$ of the subjects expressed satisfaction with the arrangement of their teeth. This frequency is consistent with satisfaction of $61.9 \%$ and $63 \%$ reported in Polish and Latvian children by Grzywacz ${ }^{14}$ and Liepa et $a^{15}$ respectively. $26.7 \%$ of the subjects felt their teeth arrangement was unsatisfactory while $11.7 \%$ were undecided. Graber and Lucker ${ }^{16}$ also reported small percentage of American children who considered their teeth to be unattractive. A statistical significant difference was observed in response to the satisfaction with teeth arrangement between the age groups with higher dissatisfaction observed in the 10-year-old children $(\mathrm{P}<0.05)$. Salonen et $a 1^{17}$ had reported that the awareness of malocclusion was higher among younger than older subjects and among those who had severe malocclusion. Grzywacz ${ }^{14}$ also suggested possibly inability to distinguish normal developmental regularities and malocclusions as the reason for difference in outcome of assessment of aesthetics in younger children and adult. However, studies have shown that dissatisfaction with dental appearance was generally related to the severity of the occlusal irregularities. ${ }^{6}$

The half of the children (51.7\%) expressed desire to straighten their teeth whereas 35\% were not interested in orthodontic treatment and $13.3 \%$ were uncertain. There was no significant association found between concern for dental aesthetics and desire for orthodontic treatment among the sexes with similar frequencies of $18.2 \%$ and $16.7 \%$ in boys and girls respectively who were dissatisfied with their teeth arrangement and desired to have orthodontic treatment to straighten them. However, less orthodontic concern was shown by the boys (9\%) compared to $2 \%$ of the girls. Also, the frequency of $37 \%$ girls who were satisfied with their dental appearance and still wanted treatment was higher than $21 \%$ observed in the boys. This study supported the observation of Gravely ${ }^{18}$ who reported that girls were more aware of malocclusion than boys and were prepared to accept treatment. Shaw ${ }^{19}$ and Pietila and Pietila ${ }^{20}$ also reported that dissatisfaction with dental appearance was more common among girls than boys. Holmes ${ }^{21}$ in his study of English children also reported that a greater proportion of females perceived themselves as having less attractive dentitions and greater treatment need despite any objective evidence to support this view. More than half of the subjects (55.8\%) considered well-aligned teeth to be important for overall facial appearance which suggested their moderate awareness of dental aesthetics.

The children were evaluated for their need of orthodontic treatment using the WHO - FDI Basic method for recording occlusal traits on the basis of clinical estimation of the adverse effects of the occlusal traits on dental aesthetics and oral function. ${ }^{11}$ Most of the school children (60\%) examined were considered not to require any orthodontic treatment. $11.7 \%$ of the children would require an urgent orthodontic treatment and this represented the proportion of children with complex / handicapping malocclusions. Orthodontic treatment was also considered necessary in 19.2\% while 9.2\% of the children would require further evaluation for orthodontic treatment need. The need for orthoodontic treatment was statistically different between the sexes. This study revealed a significant higher need for orthodontic 
Attitudes to Malocclusion in a Nigerian School Population 19

treatment in the girls than boys $(P<0.05)$. Orthodontic treatment was considered necessary in $31.5 \%$ of the girls compared to frequency of $9.1 \%$ in the boys. The higher treatment needs have also been suggested for females than males in some other studies even with different index ${ }^{21}$ used for assessment while the literature also revealed inconsistency on the role of gender.

The evaluation of normative need for orthodontic treatment and satisfaction with dental appearance revealed that half of the children (50\%) who needed professionally determined urgent orthodontic treatment expressed satisfaction with their teeth arrangement indicating moderate level of concern for malocclusion in these Nigerian children. The orthodontic concern observed could possibly be affected by the level of awareness of dental aesthetics and area of domicile of these children. Gravely $y^{18}$ had reported high level of awareness to the need for orthodontic treatment and acceptability in the region of England where high numbers of orthodontists were practicing.

\section{CONCLUSION}

The knowledge concerning the attitudes of patients to malocclusion is becoming increasingly important in orthodontics. A moderate concern for malocclusion was observed among school children in Lagos and orthodontic treatment was considered necessary and urgent in about thirty percent of these children with a significant higher need in the girls.

\section{References}

1 Standardisation of reporting of dental diseases and condition. 6. The assessment of handicapping dentofacial anomalies. Technical Reporting Series, No. 242 Geneva, World Health Organisation, 1962.

2 Gosney MBE. An Investigation into some of the factors influencing the desire for orthodontic treatment. Br J Orthod 1986; 13: $87-94$.
3. Birkeland $K$, Bøe OA, Wisth PJ. Orthodontic concern among 11-year-old children and their parents compared with orthodontic treatment need assessed by Index of Orthodontic Treatment Need. Am J Ortho Dentofacial Orthop 1996; 110: $197-205$.

4 Stenvik A, Espeland L, Berset GP, Eriksen HM. Attitudes to malocclusion among 18and 35-year-old Norwegians. Community Dent Oral Epidemiol 1996; 24: 390 - 3.

5. Al-Sarheed M, Bedi R, Hunt NP. Orthodontic treatment need and self-perception of 1116-year-old Saudi Arabian children with a sensory impairment attending special schools. J Orthod 2003; 30: $39-44$.

6. Mugonzibwa ME, Kuijpers-Jagtman, AM, Van't Hof MA, Kikwilu EN. Perceptions of dental attractiveness and orthodontic treatment need among Tanzanian children. Am J Orthod Dentofacial Orthop 2004; 125: 433-4.

7. Shaw WC, Lewis HG, Roberston NRE. Perception of malocclusion. Br Dent J 1975; 138: $211-6$.

8. Espeland LV, Grønlund G, Stenvik A. Concern for dental appearance among young adults in region with low uptake of orthodontic treatment. Community Dent Oral Epidemiol 1993; 21: 151-7.

9. Yeh M, Koochek A, Vlaskalic V, Boyd R, Richmond $S$. The relationship of 2 professional occlusal indexes with patients' perceptions of aesthetics, functions, speech, and orthodontic treatment need. Am J Orthodontics and Dentofacial Orthopedics 2000; 118: $421-428$.

10. Birkeland $\mathrm{K}, \mathrm{B} \varnothing e \mathrm{OA}$, Wisth PJ. Relationship between occlusion and satisfaction with dental appearance in orthodontically treated and untreated groups. A longitudinal study among 11 - and 15-year-olds and their parents. Journal of Orofacial Orthopedics $2000 ; 60: 292-307$

11. Bezroukov, V, Freer TJ, Helm S et al . Basic method for recording occlusal traits. BUL WHO. 1979: 57: 955 - 61.

12. Landis JR, Koch GG. The measurement of observer agreement for categorical data. Biometrics 1977; 33: $159-174$.

( C CMS UNIBEN JMBR 2006; 5 (1) : 16-23 
20 Journal of Medicine and Biomedical Research

13. Dean, AG, Dean, JA, Coulombier, D et al. Epi Info, Version 6 : A word - Processing, Database and Statistics Program for Public Health on IBM- Compatible Microcomputers. Centers for Disease Control and Prevention, Atlanta, Georgia, U.S.A., 1985.

14. Grzywacz I. The value of the aesthetic component of the Index of Orthodontic Treatment Need in the assessment of subjective orthodontic treatment need. Eur J Orthod 2003; 25: 57-63.

15. Liepa A, Urtane I, Richmond S, Dunstan F. Orthodontic treatment need in Latvia. Eur J Orthod 2003; 25: 279-284

16. Graber LW, Lucker GW. Dental esthetic selfevaluation and satisfaction. Am. J. Orthod 1980; 77: 163 - 73 .

17. Salonen L, Mohlin B, Gotzlinger B. and Hellden, L. Need and Demand for orthodontic treatment in an adult Swedish population. Eur. J. Orthod 1992; 14 : 359 368.

18 Gravely, JF. A study of need and demand for orthodontic treatment in two contrasting National Health Service Regions. Brit. J. Orthod 1990; $17: 287$ - 92 .

19 Shaw, WC. Factors influencing the desire for orthodontic treatment. Eur. J. Orthod 1981; 3: $151-162$.

20. Pietila T, Pietila I. Parents' views on their own child's dentition compared with an orthodontist, assessment. Eur. J. Orthod 1994 ; 16: $309-316$.

21. Holmes A. The subjective need demand for orthodontic treatment. Brit. J Orthod 1992 ; 19 : $287-97$. 


\section{Table 1: Attitudes to Malocclusion}

A. Are you satisfied with the arrangement of your teeth?

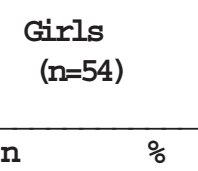

$$
\text { Boys }
$$

Total

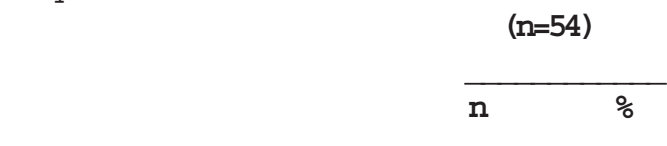

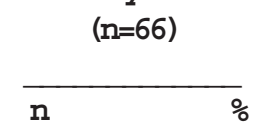

$(n=120)$

\begin{tabular}{lrrrrrr}
\hline Yes & 35 & 64.8 & 39 & 59.1 & 74 & 74.7 \\
No & 11 & 20.4 & 21 & 31.8 & 32 & 26.7 \\
Don't Know & 8 & 14.8 & 6 & 9.1 & 14 & 11.7
\end{tabular}

$X^{2}=2.45$

d.f. $=2 \quad p>0.05$

B. Do you want to have your teeth straightened?

\begin{tabular}{|c|c|c|c|c|c|c|}
\hline & \multicolumn{2}{|c|}{$\begin{array}{c}\text { Girls } \\
(n=54)\end{array}$} & \multicolumn{2}{|c|}{$\begin{array}{c}\text { Boys } \\
(n=66)\end{array}$} & \multicolumn{2}{|c|}{$\begin{array}{l}\text { Total } \\
(n=120)\end{array}$} \\
\hline & $\mathrm{n}$ & $\%$ & $\mathrm{n}$ & $\%$ & $\mathrm{n}$ & $\%$ \\
\hline Yes & 31 & 57.4 & 31 & 47.0 & 62 & 51.7 \\
\hline No & 14 & 25.9 & 27 & 41.0 & 42 & 35.0 \\
\hline \multirow[t]{2}{*}{ Don't know } & 9 & 16.7 & 8 & 12.0 & 16 & 13.3 \\
\hline & & & & $X^{2}=3.01$ & d.f. $=2$ & $p>0.05$ \\
\hline
\end{tabular}

C. Do you consider well-aligned teeth important for overall facial appearance?

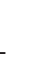

facial appearance?

\begin{tabular}{|c|c|c|c|c|c|c|c|}
\hline & & & & \\
\hline & $\mathrm{n}$ & $\%$ & $\mathrm{n}$ & $\%$ & & $\mathrm{n}$ & $\%$ \\
\hline Yes & 29 & 53.8 & 38 & 57.6 & & 67 & 55.8 \\
\hline No & 9 & 16.7 & 15 & 22.7 & & 24 & 20.0 \\
\hline Don't Know & 16 & 29.6 & 13 & 19.7 & & 29 & 24.2 \\
\hline & & & & $X^{2}=1.84$ & d.f $=2$ & & \\
\hline
\end{tabular}

\section{Table 2: Age Distribution of Satisfaction with Arrangement of Teeth}

\begin{tabular}{|c|c|c|c|c|c|c|c|c|c|}
\hline \multirow{2}{*}{$\begin{array}{l}\text { Satisfaction } \\
\text { with teeth } \\
\text { arrangement }\end{array}$} & \multicolumn{2}{|c|}{10 years } & \multicolumn{2}{|c|}{11 years } & \multicolumn{2}{|c|}{12 years } & & \multicolumn{2}{|c|}{ Total } \\
\hline & $n$ & $\%$ & $\mathrm{n}$ & $\%$ & $\mathrm{n}$ & $\%$ & & $\mathrm{n}$ & $\%$ \\
\hline Yes & 22 & 44.9 & 37 & 72.5 & 15 & 75.0 & & 74 & 61.7 \\
\hline No & 16 & 32.7 & 12 & 23.5 & 4 & 20.0 & & 32 & 26.7 \\
\hline Don't Know & 11 & 22.4 & 2 & 3.9 & 1 & 5.0 & & 14 & 11.7 \\
\hline Total & 49 & 100.0 & 51 & 100.0 & 20 & 100.0 & & 120 & 100.0 \\
\hline
\end{tabular}


Table 3: Distribution of Children According to Their Need of Orthodontic Treatment

\begin{tabular}{|c|c|c|c|c|c|c|}
\hline \multirow{2}{*}{$\begin{array}{l}\text { Need of orthodontic } \\
\text { treatment }\end{array}$} & \multicolumn{2}{|c|}{ Girls } & \multicolumn{2}{|c|}{ Boys } & \multicolumn{2}{|c|}{ Total } \\
\hline & $\mathrm{n}$ & $\%$ & $\mathrm{n}$ & $\%$ & $\mathrm{n}$ & $\%$ \\
\hline Not-necessary & 28 & 51.9 & 44 & 66.7 & 72 & 60.0 \\
\hline Doubtful & 4 & 7.4 & 7 & 10.6 & 11 & 9.2 \\
\hline Necessary & 17 & 31.5 & 6 & 9.1 & 23 & 19.2 \\
\hline Urgent & 5 & 9.3 & 9 & 13.6 & 14 & 11.7 \\
\hline Total & 54 & 100.0 & 66 & 100.0 & 120 & 100.0 \\
\hline
\end{tabular}

Table 4: Distribution of Responses to Satisfaction with Teeth Arrangement and Desire to Undertake Treatment

\begin{tabular}{|c|c|c|c|c|}
\hline & \multicolumn{2}{|c|}{$\begin{array}{l}\text { Girls } \\
(n=54)\end{array}$} & \multicolumn{2}{|c|}{$\begin{array}{c}\text { Boys } \\
(n=66)\end{array}$} \\
\hline & $\mathbf{N}$ & $\%$ & $\mathbf{N}$ & $\%$ \\
\hline Dissatisfied, desired treatment & 9 & 16.7 & 12 & 18.2 \\
\hline Dissatisfied, did not want treatment & 1 & 1.9 & 6 & 9.1 \\
\hline Satisfied, desired treatment & 20 & 37 & 14 & 21.2 \\
\hline Satisfied, did not want treatment & 12 & 22.2 & 21 & 31.8 \\
\hline Indecisive responses & 12 & 22.2 & 13 & 19.7 \\
\hline
\end{tabular}

Table 5: Satisfaction with Dental Aesthetics In Relation to Orthodontic Treatment Need

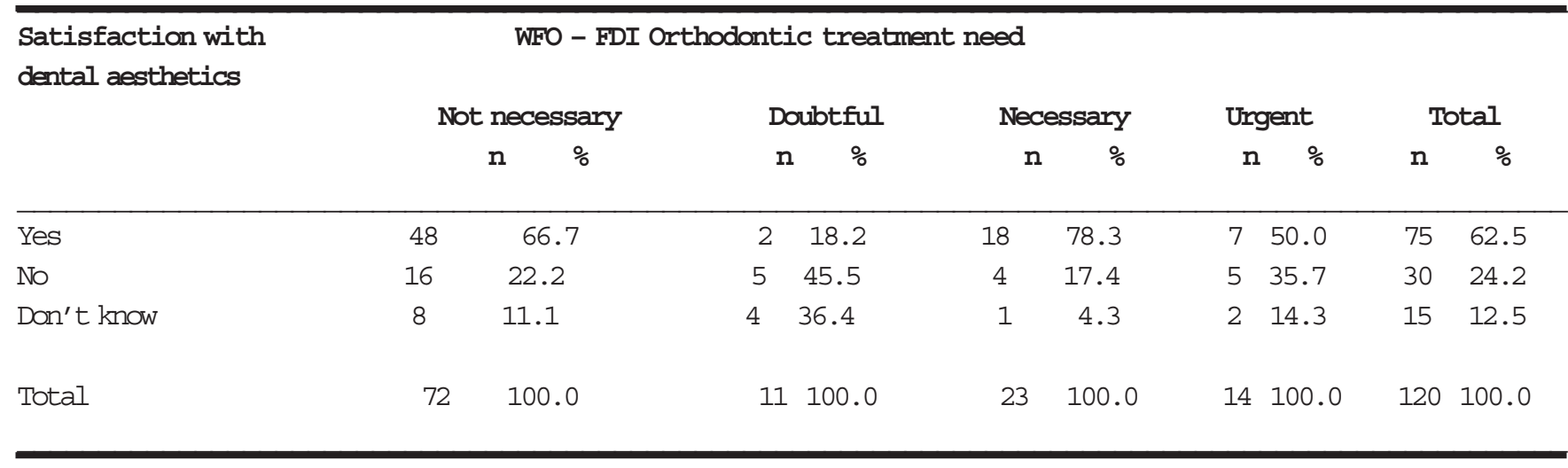

$$
\mathrm{X}^{2}=14.5 \text { d.f. }=6 \quad \mathrm{p}<0.05
$$




\section{APPENDIX}

The need for orthodontic treatment was classified into four groups using WHO-FDI Basic method for recording occlusal traits (Bezroukov et al, 1979)

a urgent: Extreme cases with esthetic or functionally handicapping anomalies b. necessary: Child showing some of risks of caries, periodontal disease, trauma or root resorption; or masticatory disturbances; socio-psychological disturbances

c doubtful: Cases that should be monitored before making any final decision

d. not necessary 